\title{
OS AGENTES DA ECONOMIA CHILENA: OS PERFIS DOS CHICAGO BOYS E OS MONGES DA CIEPLAN
}

\author{
Felipe Alejandro Guerrero Rojas ${ }^{1}$
}

\begin{abstract}
Resumo
O objeto deste artigo são os economistas dirigentes-políticos ligados ao grupo dos Chicago Boys e da CIEPLAN que participaram, respectivamente, do governo de Augusto Pinochet e de Patricio Aylwin. O objetivo é expor as características desses dois perfis de economistas e também fazer uma análise das semelhanças e diferenças. Para tanto, fez-se uso da prosopografia de 31 agentes, 23 Chicago Boys e 8 monges da CIEPLAN, e levantaram-se dados referentes à formação escolar, à herança política e à participação em partidos políticos. Esses dados foram levantados através dos dicionários biográficos. Verificou-se que, a partir do mandato do presidente Jorge Alessandri (19581964), a equipe econômica do governo contou com a presença de economistas. Essa presença cresceu na equipe econômica dos governos posteriores e esse crescimento, comparado com o de demais profissionais, deu-se tanto pelo número de cientistas econômicos como pelo tempo de mandato dos mesmos. $\mathrm{Na}$ análise de perfis dos economistas dirigentes-políticos, percebeu-se que a pós-graduação influenciou na formação ideológica dos Chicago Boys, mas não teve influência na formação dos monges da CIEPLAN. Tanto a herança política quanto a participação em partidos políticos tiveram pouco peso para o grupo dos Chicago Boys, mas tiveram peso no grupo monges da CIEPLAN. Assim, fica aberta a discussão sobre a formação ideológica e a influência dos partidos para os agentes da CIEPLAN. A relevância do presente trabalho é apresentar de forma empírica os perfis dessa nova elite política no Chile.
\end{abstract}

Palavras-Chave: Economistas, Chicago Boys, Monges da CIEPLAN, Elite Política.

\section{Resumen}

El objeto de este artículo son los economistas dirigentes-políticos vinculados al grupo de los Chicago Boys y CIEPLAN que participaron, respectivamente, del gobierno de Augusto Pinochet y Patricio Aylwin. El objetivo es exponer las características de estos dos perfiles de los economistas y también hacer un análisis de las similitudes y diferencias. Para ello, se hizo el uso de prosopografía de 31 agentes (23 Chicago Boys y 8 monjes de la CIEPLAN) y se recolectaron datos relativos a la educación escolar, a la herencia política y a la participación en los partidos políticos; esos datos fueron recogidos a través de los diccionarios biográficos. Se descubrió que, a partir de la administración del Presidente Jorge Alessandri (1958-1964), el equipo económico del Gobierno tuvo la presencia de los economistas. Esa presencia creció en el equipo económico de los gobiernos posteriores y ese crecimiento, en comparación con el de otros profesionales, se dio tanto por el número de científicos económicos como cuanto a su tiempo de mandato. En el análisis de los perfiles de los líderes políticos y de los economistas, se observó que la graduacion influyó en la formación ideológica de los Chicago Boys, pero no influyó en la formación de los monjes de la CIEPLAN. Tanto la herencia política cuanto la participación en los partidos políticos tenían poco peso en el grupo de los Chicago Boys, pero los monjes tenían un grupo de destaque en la CIEPLAN. Por lo tanto, la discusión sobre la formación ideológica y la influencia de los partidos en los agentes de la CIEPLAN está abierta. La relevancia de este trabajo es la de presentar empíricamente los perfiles de esas nuevas élites políticas en Chile.

Palabras-Claves: Economistas. Chicago Boys. Monjes de la CIEPLAN. Elíte Política.

\footnotetext{
${ }^{1}$ Mestre em Ciência Política pelo Programa de Pós-Graduação de Ciência Política da UFPR.
} 


\begin{abstract}
The objects of this article are the economists political leaders linked to the group of the Chicago Boys and CIEPLAN who participated, respectively, of the government of Augusto Pinochet and Patricio Aylwin. The goal is to expose the technical features of both economist profiles and analyze their similarities and differences. Therefore was used the prosopography of 31 agents, 23 Chicago Boys and 8 monks from CIEPLAN, and rose data, through biographical dictionaries, about academic training, political heritage and participation in political parties. It was found that since Jorge Alessandri's presidential term (1958-1964) the government's economic team was attended by economists. That presence grew in the later governments compared to that of other professionals, both in number and time of office. In the profile analysis of the economists political leaders, it was noticed that the post-graduation influenced the ideological formation of the Chicago Boys, but not of the CIEPLAN monks. Both, political heritage and participation in political parties had little weight to the group of the Chicago Boys, but had weight in the group of CIEPLAN monks. Thus, it is open to discussion the ideological formation and influence of the parties to the agents of CIEPLAN. The relevance of this work is to provide, empirically, the new profiles of these new political elite in Chile.
\end{abstract}

Keywords: Economists. Chicago Boys. CIEPLAN monks. Political elite.

\title{
1. INTRODUÇÃO
}

Na América Latina, os economistas consolidaram-se em posições centrais dentro do aparelho do Estado, que antes eram ocupadas pelos engenheiros e advogados. Segundo a literatura, existem dois motivos para a consolidação dos economistas no governo. $\mathrm{O}$ primeiro é o fato de esses representarem profissionais que são vistos como portadores de soluções para superar dificuldades de ordem econômica (desemprego, inflação, crises financeiras, entre outras). O segundo, o surgimento de instituições de planejamento e burocracia econômica estatal (MARKOFF e MONTECINOS, 1994; LOUREIRO, 1997).

Além da consolidação desses profissionais no governo, outra questão importante é diferenciar o perfil dos economistas. Segundo Maria Rita Loureiro (1997), há dois perfis de carreira seguidos pelos economistas no governo. O primeiro se trata de jovens economistas que ingressam através de concurso ou contratação direta em órgãos públicos ligados à gestão econômica. Nessas instituições, eles passam o maior tempo da sua vida profissional, consolidando uma carreira que pode alcançar até escalões de níveis intermediários nos organismos governamentais. Esse perfil é definido como funcionárioeconomista ${ }^{2}$. O segundo perfil é daqueles que atuam no alto escalão do governo, os quais são denominados economistas dirigentes-políticos. Esses profissionais são recrutados pelo

\footnotetext{
2 Sobre um estudo acerca do funcionário-economista, ver Gouvêa (1994).
} 
governo no meio universitário. Geralmente são professores "brilhantes" que através de suas consultorias se tornaram conhecidos no meio empresarial. Para o economista dirigente-político, ser convidado para compor o governo é o reconhecimento de sua competência técnica (LOUREIRO, 1997. pp. 88-89).

No caso do Chile, a presença dos economistas como dirigentes-políticos se iniciou no governo conservador de Jorge Alessandri (1958-1964) e foi crescendo nos governos posteriores. Mas foi a partir de 1970 que a participação dos economistas se deu por grupos homogêneos, de tal modo que, nos três governos seguintes, o governo socialista de Salvador Allende (1970-1973), a ditadura militar do general Augusto Pinochet (1973-1990) e o governo do democrata cristão Patricio Aylwin (1990-1994) contaram, respectivamente, com a presença majoritária de economistas ligados à CEPAL (Comissão Econômica para América Latina e Caribe), a Universidade de Chicago e a CIEPLAN (Corporación de Estudios para Latinoamérica).

Diante desse breve contexto, o tema deste trabalho é a participação dos economistas em altos cargos no governo chileno, focando naqueles ligados à Universidade de Chicago, à CIEPLAN, aos Chicago Boys e aos monges da CIEPLAN.

Sabe-se que, nesse tema (a presença dos economistas no governo chileno) existem três tipos de estudos com pouca literatura. O primeiro deles parte da análise dos economistas enquanto uma elite política e seu papel no governo (MARKOFF e MONTECINOS, 1994; MONTECINOS, 1997/1998). O segundo estuda a formação da tecnocracia chilena e, em seguida, descreve que parte dessa tecnocracia corresponde aos profissionais oriundos da economia (SILVA, 1991/2006/2010). E o último trata de estudos sobre os Chicago Boys, seja com relação à participação destes e à política econômica chilena durante a ditadura militar (FONTAINE, 1988; DÉLANO e TRASLAVIÑA, 1989; HUNNEUS, 1998) ou no tocante à formação dos Chicago Boys (VALDÉS, 1989/1995).

Assim, a dificuldade é encontrar na literatura pesquisas que tenham como horizonte traçar e apresentar empiricamente os perfis desses agentes da economia. Dito isso, este trabalho tem como objetivo preencher essa lacuna, ou seja, fazer um estudo do perfil dos Chicago Boys e dos monges ${ }^{3}$ da CIEPLAN. Como metodologia, foi empregada a prosopografia, uma investigação das características comuns desses agentes através de usos de dicionários biográficos ${ }^{4}$.

\footnotetext{
3 Segundo Silva (1991/2010), foi Fernando Henrique Cardoso que nomeou de "monges" os economistas ligado a CIEPLAN que foram recrutados para o governo do Patricio Aylwin.

4 Foram utilizados os seguintes dicionários: Diccionario biográfico de Chile 1984-1986 e Biografías de Chilenos1876-1973: Miembros de los Poderes Ejecutivo, Legislativo y Judicial.
} 
Este artigo é dividido em duas partes. A primeira faz um estudo das equipes econômicas formadas de 1958 a 1994 no Chile com o objetivo de discorrer e apresentar empiricamente o crescimento do economista dirigente-político no Chile. A segunda estuda os perfis dos dois grupos principais de economistas no Chile entre o período de 1973 a 1994, focando em três variáveis: formação escolar (onde se fez o curso de graduação e o de pós-graduação); se esses agentes possuem uma herança política; e, finalmente, se pertence a algum partido político no Chile. Foram descartadas as variáveis de localização e de gênero. A variável de localização por se tratar de um país pequeno e a de gênero, pelo fato de quase todos os casos, exceto um, serem homens.

\section{A ASCENSÃO DOS ECONOMISTAS NO CHILE}

No Chile, os economistas também foram consolidando suas carreiras dentro do Estado. A ascensão desses em posições-chave do poder político no Chile seguiu uma trajetória gradual e progressiva. Essa ascensão se iniciou no governo de Jorge Alessandri, consolidou-se no governo de Pinochet e se fortaleceu no governo Patricio Aylwin. Durante a presidência de Jorge Alessandri (1958 - 1964), pela primeira vez na história chilena, o cargo de Diretor de Orçamento (DIPRES) foi ocupado por um economista, como também o Ministério da Economia. Esses cargos, em outros governos, eram preenchidos por profissionais de formação na área de engenharia ou do direito. Já no governo de Eduardo Frei Montalva (1964 - 1970), os profissionais da economia passaram a ocupar outros cargos como a presidência do Banco Central, a direção da Oficina de Educación y Planificácion (ODEPLAN) e o Ministério da Fazenda, além da DIPRES. No mandato do presidente socialista Salvador Allende $(1970$ - 1973), a participação dos economistas no aparelho estatal aumenta: as pastas da ODEPLAN, Ministério da Economia, DIPRES e a Presidência do Banco Central passam a ser ocupadas por economista por períodos maiores que no governo anterior. (MARKOFF e MONTECINOS, 1994, pp.3-4).

Segundo Montecinos (1997, p. 2), com o golpe militar, o ditador General Pinochet convidou um grupo de economistas chamados Chicago Boys para participar do governo e construir uma nova política econômica no Chile. Esse grupo de economistas dominou diversas áreas da política e da economia, como, por exemplo, a pasta do Ministério da Fazenda. Desse modo, diminuiu a presença dos advogados, engenheiros e demais profissionais nas tomadas de decisões na área da economia no Estado. 
No primeiro governo democrático após o golpe de 73, a tendência de participação dos economistas no governo se fortaleceu. Esses profissionais passaram a dominar completamente o campo das decisões da política econômica no Chile, de tal forma que a equipe econômica do governo de Patricio Aylwin (1990-1994) foi composta apenas por profissionais formados nos cursos de economia de diversas faculdades do Chile.

Essa ascensão pode ser exemplificada pelos Gráficos 1 e 2. Tanto no Gráfico 1 quanto no Gráfico 2, foram selecionadas as carreiras que compuseram os ministérios ligados à formulação da política econômica no Chile no período de 1958 a 1994. Esses ministérios seriam o Ministério da Fazenda, Ministério da Economia, ODEPLAN, DIPRES e a presidência do Banco Central.

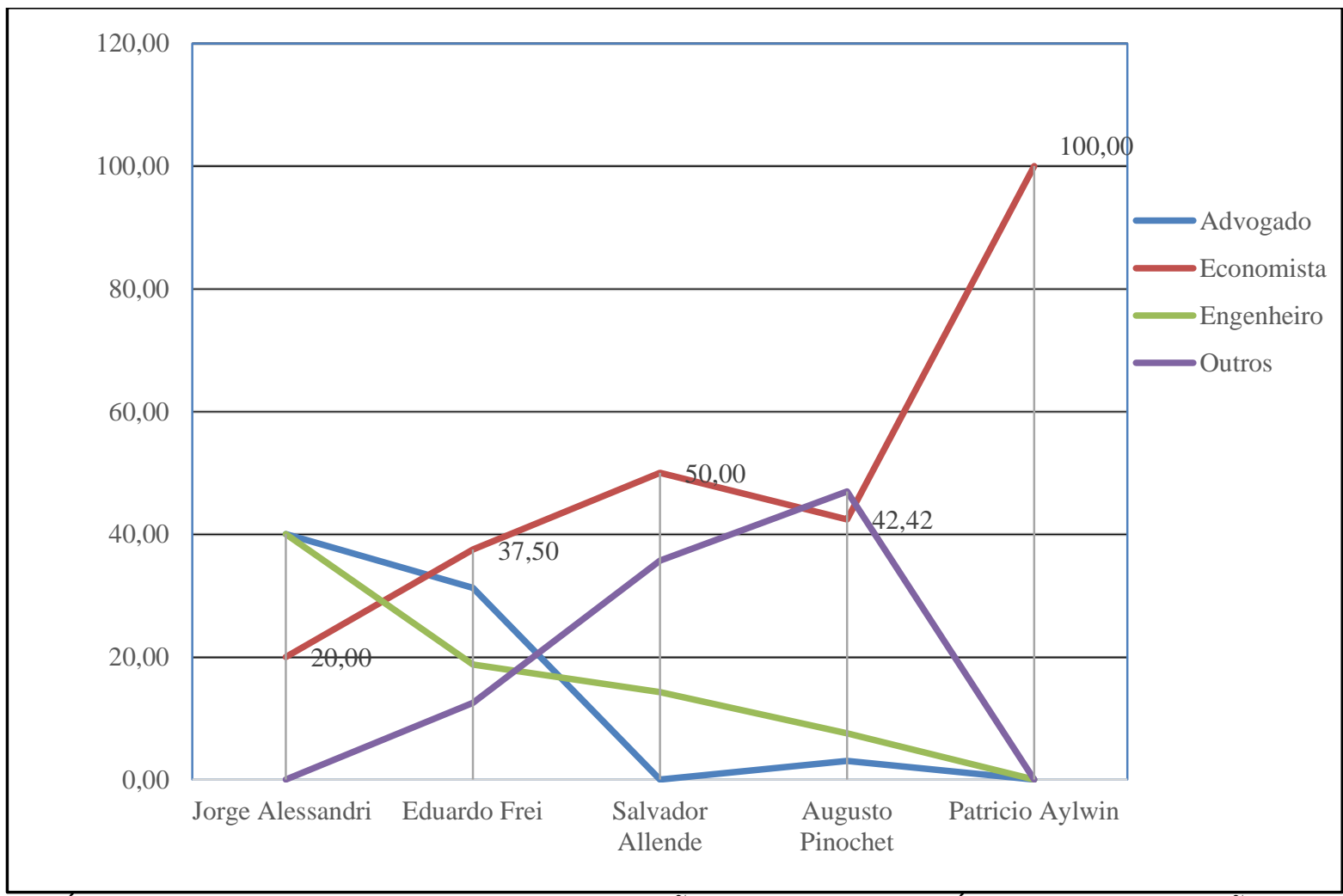

GRÁFICO 1 - PERCENTUAL DE PROFISSÕES NOS MINISTÉRIOS DE DECISÃO DA POLÍTICA ECONÔMICA DO CHILE NO PERIÓDO 1958 A 1994 (N=102) FONTE: O Autor

Conforme o Gráfico 1, o número de profissionais formados em economia teve uma ascensão na participação da equipe econômica do governo chileno. Desse modo, verifica-se que, no governo de Jorge Alessandri, a participação dos economistas era de $20 \%$. Essa participação cresce nos outros governos, de $20 \%$ passa para $37,5 \%$ durante o governo de Eduardo Frei e chega a 50\% no período comandado pelo presidente socialista Salvador Allende. $\mathrm{Na}$ ditadura militar, houve uma pequena queda de presença de 
economistas no governo: de $50 \%$ foi para $42,42 \%$. Essa queda se deu porque, durante o golpe, os militares foram nomeados para diversos altos cargos do executivo, inclusive para cargos relacionados à política econômica (Huneeus, 1988, p. 126). Na redemocratização, em 1990, a participação dos economistas chegou a 100\% durante os quatros anos de governo de Patricio Aylwin.

Outra variável interessante para analisar o aumento da participação dos economistas no governo é o tempo de mandato. A importância dessa variável é saber qual profissional permanece mais tempo na equipe econômica de um determinado governo. Algumas vezes, diante de uma instabilidade econômica, troca-se muito de ministros. Assim, esse cargo é preenchido por diversos profissionais num período curto de tempo. Um exemplo disso foi durante o governo de Salvador Allende, no qual se trocou várias vezes o cargo de Ministro da Fazenda.

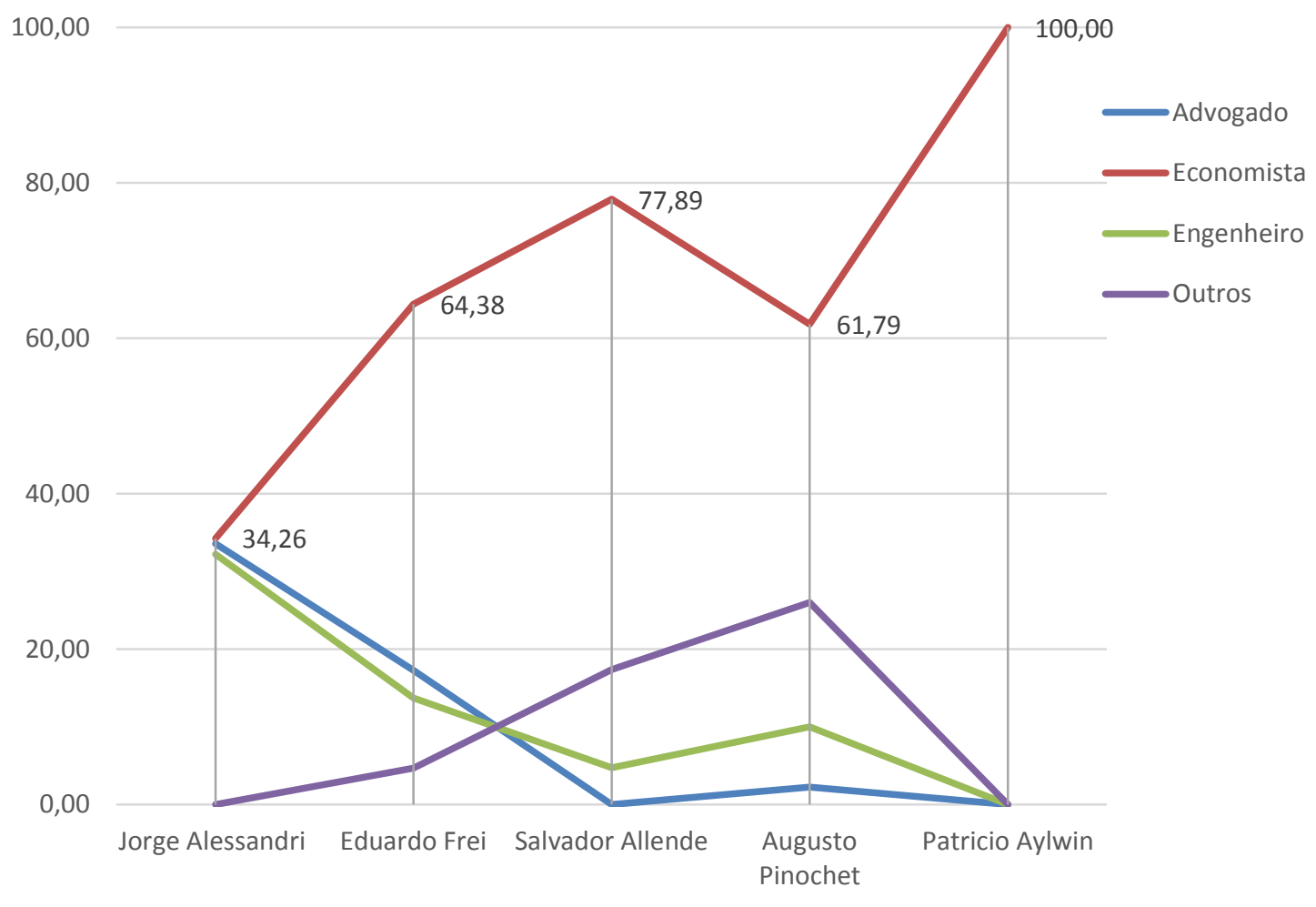

GRÁFICO 2 - PERCENTUAL DE PROFISSIONAIS POR TEMPO NOS MINISTÉRIOS DA ÁREA ECONÔMICA DO CHILE NO PERÍODO DE 1958 A 1994

FONTE: O Autor 
De acordo com o Gráfico 2, o tempo de participação dos economistas é maior que o dos demais profissionais em todos os governos entre o período de 1958 a 1994. Assim, percebe-se que, já no governo Jorge Alessandri, o tempo de mandato representa $34,26 \%$, aumentando para 64,38\% no governo do Eduardo Frei. No governo do partido socialista, chega a $77,89 \%$ e no governo ditatorial ${ }^{5}$ cai para $61,79 \%$, mas na redemocratização, chega a $100 \%$.

A partir da análise dos gráficos constatamos que é evidente que os economistas se tornaram uma nova elite política, com um campo próprio de atuação no Estado chileno. Essa elite cresceu e se consolidou com o passar dos anos, substituindo advogados e engenheiros nos cargos relacionados à Economia. Uma vez demonstrada a consolidação dos economistas dentro do governo chileno, este artigo passará a focar dois tipos de grupos de economistas que participaram do governo chileno no período de 1973 a 1990.

\section{O PERFIL DOS CHICAGO BOYS E DOS MONGES DA CIEPLAN}

Com o golpe militar no dia 11 de setembro de 1973, chega ao fim o período democrático chileno. A aplicação do decreto-lei 27, do dia 21 de setembro de 1973, estabeleceu o fim do Congresso Nacional e declarou cassadas as funções parlamentares a partir dessa data. Nesse golpe, foi formada uma junta militar, composta pelo Comandante Chefe do Exército, Augusto Pinochet Ugarte, pelo Comandante Chefe da Força Área, Gustavo Leigh Guzmán, pelo Comandante Chefe da Marinha, José Toribio Merino, e pelo General Diretor da Polícia, César Mendoza Durán. Em 1974, o ditador General Pinochet ocupa a posição de presidente do Chile. (GÓNGORA, 1981, p. 132-133).

O regime militar de Augusto Pinochet, além de cometer vários crimes contra a humanidade, mudou as estruturas do Estado e da sociedade chilena. Se, anteriormente, os governos se preocupavam em aumentar a participação do Estado para garantir melhorias através de políticas sociais para a sociedade, durante a ditadura houve uma redução do Estado chileno nos serviços oferecidos à população com a privatização da saúde, da educação, do transporte, entre outros serviços. Além disso, o governo militar desenvolveu a "sociedad de consumo": a política econômica se desenvolveu através da crescente demanda da população por bens de consumo. Isso ocorreu de tal forma que a política de consumo

\footnotetext{
${ }^{5}$ Essa queda de participação pode ser explicada por dois motivos. O primeiro foi o receio dos militares em perder força no governo de Pinochet pelos Chicago Boys. E o segundo foi que, com a derrota do Pinochet no plebiscito, os Chicago Boys decidiram se afastar do governo ditatorial.
} 
legitimou a nova ordem política e econômica, uma vez que os governos chilenos são avaliados pela sua capacidade de satisfazer as demandas por bens de consumo da sociedade. Essas reformas foram fruto da participação dos economistas chamados Chicago Boys no governo militar (SILVA, 1991).

Os Chicago Boys foram a principal equipe econômica no governo do ditador Augusto Pinochet, que idealizou e implementou o modelo econômico neoliberal no Chile. A denominação Chicago Boys surgiu por se tratar de um grupo de estudantes oriundos da Universidade Católica do Chile e da Universidade do Chile que, através do convênio UCChicago, puderam estudar no programa de pós-graduação da Escola de Economia da Universidade de Chicago (VALDÉS, 1989).

Esse contingente de estudantes, quando retornou ao Chile, formou um grupo organizado e coeso de intelectuais de cunho ideológico neoliberal que passou a reproduzir as metodologias e ideias, aprendidas em Chicago, na Faculdade de Economia da Universidade Católica do Chile. Além disso, também foram os principais opositores aos economistas ligados à CEPAL. Em 1967, esse grupo começou a difundir as ideias do neoliberalismo através de meios de comunicação tradicionais, como o caderno de economia do jornal El Mercúrio, na revista Política, Economia y Cultura, na criação da revista Qué Pasa. Também foi criado o Centro de Estudios Socioeconomicos (CESEC) e, em 1972, foi elaborada uma plataforma política econômica, a qual no futuro seria a base das políticas do governo militar, El Ladrillo. (VALDÉS, 1995).

No início do governo militar, os Chicago Boys não assumiram imediatamente cargos de alto escalão dentro da esfera estatal. No primeiro momento desse regime, foram designados para ocupar os postos no governo apenas homens de confiança das forças armadas, como os próprios militares e os economistas vinculados ao PDC 6 . Desse modo, os Chicago Boys passaram um tempo como assessores e técnicos dependentes dos mandatos dos militares antes de possuírem poder de decisão. Em 1975, os Chicago Boys elaboraram um plano econômico denominado tratamiento de shock, que foi aplicado pelo ministro da Fazenda, Jorge Cauas, e ocasionou a abertura do governo militar para a ascensão desse grupo de economistas. Dessa forma, o grupo conquistou a sua autonomia para pôr em prática as mudanças estruturais baseadas na política neoliberal (DELAÑO, TRASLAVIÑA, 1989, p. 30).

\footnotetext{
${ }^{6}$ O Partido Democrata Cristão colaborou com o golpe de 11 de setembro, contudo esse apoio não durou muito. O PDC retirou o seu apoio ao perceber que o regime militar iria durar vários anos. Consequentemente, igual aos demais partidos, o PDC teve seus direitos cassados pela junta militar, entrando na ilegalidade.
} 
Os Chicago Boys não apenas assumiram cargos importantes no governo, como também trouxeram mudanças na tomada de decisão do Estado chileno. As decisões do governo passaram a ser baseadas em princípios "técnicos e científicos" e não mais por postulados políticos e ideológicos. Esse modelo tinha a pretensão de construir uma "sociedade tecnificada"; uma sociedade onde os mais capacitados tomam decisões técnicas para as quais foram treinados. A partir desse modelo, os Chicago Boys puderam se constituir como elite política e desenvolver políticas baseadas nos princípios neoliberais. Mesmo com a redemocratização e a vitória dos partidos de oposição ao governo de Pinochet, nas eleições de 1990, o governo da Concertación não conseguiu romper com essa forma de Estado (SILVA, 2010).

Durante o regime militar, a ODEPLAN, sob a orientação dos Chicago Boys, teve um papel fundamental para estabelecer as políticas neoliberais no Chile. A ODEPLAN foi a agência estatal que reuniu um grande número de economistas e engenheiros que transformariam a economia chilena. A ODEPLAN tinha três funções essenciais. A primeira era recrutar jovens profissionais para os postos de técnicos no governo autoritário, dando capacitação administrativa e técnica. A segunda função era de elaborar as principais reformas econômicas, como, por exemplo, a privatização dos sistemas de previdência e de saúde, além da privatização de empresas estatais e do fim do Estado interventor. Por último, era função da ODEPLAN formular políticas para o combate à extrema pobreza. (HUNEEUS, 1998, p.128).

O fim da ditadura se deu através de um plebiscito nacional. A constituição aprovada em 1980 coloca que deveria acontecer um plebiscito antes de 1988 para decidir se seria mantido o governo militar de Augusto Pinochet até 1997 (a opção do “S乞”) ou se seriam convocadas as eleições presidenciais dentro de um ano após o referendum (a opção do "No"). Assim, a campanha do "No" teve duas importantes consequências. A primeira é que se formou um bloco de oposição ao regime militar, o qual governaria o Chile por 20 anos, a Concertación. E a segunda foi que reuniu os tecnocratas, tanto dos partidos de centro como de esquerda, para conjuntamente formularem um programa político comum e elaborar políticas setoriais para um governo democrático. Essa cooperação multipartidária de tecnocratas contribuiu para que o primeiro candidato pela Concertación, Patricio Aylwin, recebesse o apoio técnico necessário para a construção de um programa político e, também, na efetividade das políticas públicas durante o primeiro mandato da redemocratização. (SILVA, 2010). 
O Quadro 1 apresenta os nomes dos principais Chicago Boys e os cargos que ocuparam no governo.

\begin{tabular}{|l|l|}
\hline \multicolumn{1}{|c|}{ NOMES } & \multicolumn{1}{c|}{ CARGO NO GOVERNO } \\
\hline Álvaro Saieh & Conselheiro do Banco Central. \\
\hline Alvaro Bardón & $\begin{array}{l}\text { Conselheiro do CORFO, Presidente do Banco Central, } \\
\text { Subsecretário de Economia, Presidente do Banco do Estado. }\end{array}$ \\
\hline Alvaro Donoso & Ministro Diretor da ODEPLAN. \\
\hline Andrés Sanfuentes & $\begin{array}{l}\text { Conselheiro do Banco Central, Conselheiro da Oficina de } \\
\text { Orçamento. }\end{array}$ \\
\hline Carlos Cáceres & $\begin{array}{l}\text { Presidente do Banco Central, Ministro da Fazenda, Ministro do } \\
\text { Interior. }\end{array}$ \\
\hline Cristián Larroulet & $\begin{array}{l}\text { Assessor da ODEPLAN, Chefe de gabinete do Ministério da } \\
\text { Fazenda. }\end{array}$ \\
\hline Felipe Lamarca & Diretor do Serviço de Imposto Interno (SII). \\
\hline Hernán Büchi & $\begin{array}{l}\text { Superintendente de Bancos, Subsecretário da Saúde, Ministro } \\
\text { diretor da ODEPLAN, Ministro de Fazenda. }\end{array}$ \\
\hline Joaquín Lavín & Assessor da ODEPLAN. \\
\hline Jorge Caus & Vice-Presidente do Banco Central, Ministro da Fazenda. \\
\hline Jorge Selume & Diretor do Orçamento. \\
\hline José Piñera & Ministro do Trabalho, Ministro de Minérios. \\
\hline Juan Andrés Fontaine & Chefe do Departamento de Estudos do Banco Central. \\
\hline Juan Carlos Méndez & Diretor do Orçamento. \\
\hline Juan Villarzú & Diretor do Orçamento. \\
\hline Julio Dittborn & Subdiretor da ODEPLAN. \\
\hline María Teresa Infante & $\begin{array}{l}\text { Assessora da ODEPLAN, Subsecretária da Previdência Social, } \\
\text { Ministra do Trabalho. }\end{array}$ \\
\hline Martín Costabal & Diretor do Orçamento. \\
\hline Miguel Kast & $\begin{array}{l}\text { Ministro Diretor da ODEPLAN, Ministro do Trabalho, Vice- } \\
\text { Presidente do Banco Central. }\end{array}$ \\
\hline Pablo Baraona & $\begin{array}{l}\text { Assessor do Ministério da Agricultura, Presidente do Banco } \\
\text { Central, Ministro da Fazenda e Ministro de Minérios. }\end{array}$ \\
\hline Rolf Lüders & Ministro da Economia, Ministro da Fazenda. \\
\hline Sergio de Castro & $\begin{array}{l}\text { Assessor do Ministério da Economia, Ministro de Economia, } \\
\text { Ministro da Fazenda. }\end{array}$ \\
\hline Sergio de la Cuadra & Presidente do Banco Central, Ministro da Fazenda. \\
\hline BOYS QUE OCUPARAM POSTOS-CHAVE DRANTE O Oán
\end{tabular}

QUADRO 1 - CHICAGO BOYS QUE OCUPARAM POSTOS-CHAVE DURANTE O GOVERNO MILITAR

FONTE: Délano y Traslaviña (1989)

O primeiro governo da Concertación teve como objetivo principal manter o equilíbrio macroeconômico e diminuir as desigualdades sociais oriundas do período militar. Desse modo, a missão principal era crescer economicamente com equidade social. Assim, 
nas eleições de 1989, o candidato da Concertación, Patricio Aylwin, é eleito em dezembro com 55\% dos votos. O segundo colocado na disputa presidencial foi o Chicago Boy e ministro de Fazenda do governo militar, Hernán Buchi, que teve 28\% dos votos. E o terceiro candidato foi o empresário Francisco Errázuriz que alcançou 15\% dos votos.

O auge dos tecnocratas no governo Aylwin foi possível por três fatores. O primeiro, pela necessidade de uma forma clara e legítima para designar quem iriam ocupar os cargos do governo, tendo Aylwin declarado que os cargos governamentais seriam ocupados pelos "mais capazes" em suas áreas especificas. Desta maneira, não haveria "cotas partidárias" e, sim, seleção pelas habilidades técnicas. O segundo fator trata da melhoria da formação da classe política do centro e da esquerda. Como tanto os exilados quanto aqueles que permaneceram no Chile frequentaram cursos de pós-graduação de excelência acadêmica, passou a existir um grande número de pessoas possuidoras de alto nível de formação no processo de tomada de decisão. E o terceiro repousa na preocupação do governo Aylwin em preservar a estabilidade macroeconômica para garantir a governabilidade e prolongar a Concertación no Poder Executivo chileno. A importância da tecnocracia nessa presidência resultou na participação dos investigadores ligados à CIEPLAN (Corporación de Estudios para Latinoamérica) (SILVA, 2010).

Os monges da CIEPLAN foram tais investigadores associados a esse instituto de pesquisa, privado, sem fins lucrativos. A CIEPLAN foi criada em 1976 com o objetivo de elaborar trabalhos sobre a política pública no Chile e na América Latina.

No período da ditadura militar, esses investigadores focaram em atividades de monitoramento das políticas econômicas implantadas pelos Chicago Boys, de tal forma que se tornaram a principal oposição destes no campo teórico econômico. Diferentemente dos Chicago Boys, os pesquisadores da CIEPLAN estudaram em distintos centros de pósgraduação no exterior, o que possibilitou a formação qualificada desses agentes para a elaboração de trabalhos altamente sofisticados, nos quais depositavam suas críticas à política econômica do período de 1973 a 1990 (SILVA, 1991).

Com a redemocratização chilena, os principais cargos no governo de Patricio Aylwin foram ocupados pelos monges da CIEPLAN. Assim, estes puderam consolidar políticas econômicas baseadas na manutenção do equilíbrio econômico com aumento de gastos públicos para diminuir as desigualdades sociais herdadas do período anterior. $\mathrm{O}$ sucesso dessa gestão econômica foi tão grande que muitos consideram Alejandro Foxley, o principal economista na elaboração do plano econômico, como futuro candidato à presidência do Chile. (SILVA, 2010). 
Os monges da CIEPLAN e os cargos que ocuparam estão descritos no Quadro 2.

\begin{tabular}{|l|l|}
\hline \multicolumn{1}{|c|}{ NOMES } & \multicolumn{1}{c|}{ CARGO NO GOVERNO } \\
\hline Alejandro Foxley & Ministro da Fazenda. \\
\hline Andrés Velasco & Chefe de Gabine do Ministério da Fazenda \\
\hline Jorge Marshall & Ministro da Economia. \\
\hline José Pablo Arellano & Diretor de Orçamento. \\
\hline Manuel Marfán & Coordenador de Políticas do Ministério da Fazenda \\
\hline Pablo Piñera & Subsecretário do Ministério da Fazenda. \\
\hline René Javier Cortázar Sanz & Ministro do Trabalho. \\
\hline Ricardo Ffrench-Davis & Diretor de Estudos do Banco Central. \\
\hline
\end{tabular}

QUADRO 2 - MONGES DA CIEPLAN QUE OCUPARAM POSTOS-CHAVE DURANTE O GOVERNO DE PATRICIO AYLWIN

FONTE: O AUTOR

\section{UNIVERSIDADES, HERANÇA POLÍTICA E PARTICIPAÇÃO PARTIDÁRIA}

Como dito anteriormente, as variáveis selecionadas para traçar o perfil dos dois grupos de profissionais foram referentes a educação, genealogia política e participação partidária. Apenas foram encontradas informações completas para 31 agentes.

O Quadro 3 e o Quadro 4 descrevem a formação desses indivíduos: em quais universidades e centros de pós-graduação estudaram.

\begin{tabular}{|c|l|r|r|}
\hline GRUPO & \multicolumn{1}{|c|}{ UNIVERSIDADE } & ABS & \multicolumn{1}{c|}{$(\%)$} \\
\hline \multirow{4}{*}{ Chicago Boys } & Universidade Católica do Chile & 17 & 73,91 \\
\cline { 2 - 4 } & Universidade Católica de Valparaíso & 1 & 4,35 \\
\cline { 2 - 4 } & Universidade do Chile & 5 & 21,74 \\
\hline \multirow{2}{*}{ TOTAL } & Universidade Católica do Chile & 23 & 100,00 \\
\hline \multirow{4}{*}{$\begin{array}{c}\text { Monges da } \\
\text { CIEPLAN }\end{array}$} & Universidade Católica de Valparaíso & 4 & 50,00 \\
\cline { 2 - 4 } & Universidade de Santiago & 1 & 12,50 \\
\cline { 2 - 4 } & Universidade do Chile & 1 & 12,50 \\
\cline { 2 - 5 } & Universidade do Yale & 1 & 12,50 \\
\hline \multirow{2}{*}{ TOTAL } & & 1 & 12,50 \\
\hline
\end{tabular}

QUADRO 3 - UNIVERSIDADES POR GRUPO DE ECONOMISTAS

FONTE: O Autor 


\begin{tabular}{|c|l|r|r|}
\hline GRUPO & \multicolumn{1}{|c|}{ CENTRO DE POS GRADUAÇÃO } & ABS & \multicolumn{1}{c|}{$\%$} \\
\hline \multirow{4}{*}{ Chicago Boys } & Universidade da Columbia & 2 & 8,70 \\
\cline { 2 - 4 } & Universidade de Harvard & 2 & 8,70 \\
\cline { 2 - 4 } & Universidade de Chicago & 18 & 78,26 \\
\cline { 2 - 4 } & Sem pós-graduação & 1 & 4,35 \\
\hline \multirow{4}{*}{ TOTAL } & Instituto Tecnológico de Massachusetts & 1 & 100,00 \\
\hline \multirow{4}{*}{$\begin{array}{l}\text { Monges da } \\
\text { CIEPLAN }\end{array}$} & Universidade de Boston & 1 & 12,50 \\
\cline { 2 - 4 } & Universidade de Harvard & 3 & 12,50 \\
\cline { 2 - 4 } & Universidade de Wisconsin & 1 & 12,50 \\
\cline { 2 - 4 } & Universidade de Yale & 1 & 12,50 \\
\cline { 2 - 4 } & Universidade de Chicago & 8 & 12,50 \\
\hline \multirow{2}{*}{ TOTAL } & & 100,00 \\
\hline
\end{tabular}

QUADRO 4 - CENTROS DE PÓS-GRADUAÇÃO POR GRUPO DE ECONOMISTAS

FONTE: O Autor

No Quadro 3, percebe-se que, em ambos os grupos, a Universidade Católica do Chile teve maior peso. No grupo dos Chicago Boys, foram 17 indivíduos que cursaram a Universidade Católica do Chile, representando a grande maioria. Já no grupo dos monges da CIEPLAN, a metade estudou na Universidade Católica do Chile.

Segundo o Quadro 4, como era esperado no grupo dos Chicago Boys, foi a Universidade de Chicago que teve maior influência. Dos 23 economistas, 18 cursaram o programa de pós-graduação da Universidade de Chicago. Entretanto, 5 Chicago Boys cursaram em outras instituições universitárias a pós-graduação. Essa formação dos Chicago Boys em outras universidades, segundo Valdés (1989), ocorreu pelo fato de alguns estudantes de economia terem buscado outras instituições de ensino para não serem chamados de Chicago Boys, embora esses indivíduos defendessem a ideologia neoliberal e fossem partidários do golpe militar. Ademais, teve uma ligeira maior influência a pósgraduação na Escola de Chicago do que a graduação na Universidade Católica do Chile.

Continuando com o Quadro 4, os monges da CIEPLAN não concentraram seus estudos tão somente em um centro de pós-graduação: a universidade que maior presença teve foi a Universidade de Harvard. Nesta instituição estudaram 3 economistas, enquanto que o restante, os 5 economistas, ingressaram em outros programas de pós-graduação em ciências econômicas. Assim, uma única universidade, para este grupo, não possui grande força na formação destes.

Outra questão analisada é se esses economistas dirigentes-políticos possuíam parentes que tivessem participação em cargos no espaço político. Foi considerado como 
parentesco apenas o respectivo pai. A mãe foi descartada, pois a participação da mulher na política chilena durante o período selecionado é insignificante. Os cargos selecionados foram de deputados, senadores, prefeitos, juízes e ministros. Dos 31 agentes, acharam-se informações apenas para 26 indivíduos.

\begin{tabular}{|c|l|r|r|}
\hline \multirow{2}{|c|}{ GRUPO } & HERANÇA POLÍTICA & ABS & $\%$ \\
\hline \multirow{4}{*}{ Chicago Boys } & Sim & 4 & 17,39 \\
\cline { 2 - 4 } & Não & 16 & 69,57 \\
\cline { 2 - 4 } & Sem informação & 3 & 13,04 \\
\hline \multirow{2}{*}{ TOTAL } & Sim & 23 & 100,00 \\
\hline \multirow{3}{*}{ Monges da CIEPLAN } & Não & 4 & 50,00 \\
\cline { 2 - 5 } & Sem informação & 2 & 25,00 \\
\hline \multicolumn{2}{|l|}{ TOTAL } & 2 & 25,00 \\
\hline
\end{tabular}

QUADRO 5 - HERANÇA POLÍTICA POR GRUPO DE ECONOMISTAS FONTE: O Autor

Como descreve o Quadro 5, existe uma diferença na herança política entre o grupo dos Chicago Boys e o da CIEPLAN. A herança política teve pouco impacto nos Chicago Boys. Para 16 economistas, o pai não possuiu participação na política. Assim, o parentesco político direto, ou seja, de pai para filho, não teve importância para a ascensão desses profissionais em cargos do Executivo no Chile.

No caso dos agentes da CIEPLAN, a falta de dados não permite fazer qualquer análise sobre a influência da herança política para esses economistas.

No estudo da participação em partidos políticos, considerou-se apenas a filiação. Assim, o Quadro 6 descreve em quais partidos esses dois perfis tiveram presença e o Quadro 7 agrega o número de filiados por categoria.

\begin{tabular}{|c|l|r|}
\hline GRUPO & \multicolumn{1}{|c|}{ PARTIDO } & \multicolumn{1}{|c|}{ ABS } \\
\hline \multirow{4}{*}{ Chicago Boys } & União Democrata= Independiente & 5 \\
\cline { 2 - 3 } & Partido Democrata Cristão & 1 \\
\cline { 2 - 3 } & Autônomos & 16 \\
\cline { 2 - 3 } & Sem informação & 1 \\
\hline \multirow{4}{*}{$\begin{array}{c}\text { Monges da } \\
\text { CIEPLAN }\end{array}$} & Partido Democrata Cristão & 4 \\
\cline { 2 - 3 } & Partido pela Democracia & 1 \\
\cline { 2 - 3 } & Partido Socialista & 1 \\
\cline { 2 - 3 } & Autônomos & 2 \\
\hline
\end{tabular}

QUADRO 6- PARTIDO POR GRUPO DE ECONOMISTAS

FONTE: O Autor 


\begin{tabular}{|c|c|c|c|}
\hline GRUPO & FILIAÇÃO & ABS & $\%$ \\
\hline \multirow{3}{*}{ Chicago Boys } & Sim & 6 & 26,09 \\
\hline & Não & 16 & 69,57 \\
\hline & Sem informação & 1 & 4,35 \\
\hline \multicolumn{2}{|l|}{ TOTAL } & 23 & 100,00 \\
\hline \multirow{2}{*}{$\begin{array}{l}\text { Monges da } \\
\text { CIEPLAN }\end{array}$} & Sim & 6 & 75,00 \\
\hline & Não & 2 & 25,00 \\
\hline \multicolumn{2}{|l|}{ TOTAL } & 8 & 100,00 \\
\hline
\end{tabular}

QUADRO 7 - FILIAÇÃO POR GRUPO DE ECONOMISTAS

FONTE: O Autor

Desse modo, o Quadro 6 e o Quadro 7 expõem a pouca participação dos economistas de Pinochet nos partidos políticos: há uma grande quantidade de economistas não-filiados (16 indivíduos). Ou seja, esse perfil de economista dirigente-político teve pouco interesse em participar na política partidária. Já o outro perfil de economista apresenta um resultado inverso, 6 dos 8 economistas da CIEPLAN são filiados a algum partido político, sendo que são 4 no Partido Democrata Cristão, 1 no Partido por La Democracia e 1 no Partido Socialista. Assim, esse perfil de economista dirigente-político tem uma participação em outro espaço além do governo, participando em partidos políticos, principalmente no Partido Democrata Cristão.

\section{CONCLUSÃO}

Este trabalho discorreu sobre os economistas no Chile. Procurou mostrar, apoiando-se em dados, a ascensão em espaços específicos de decisão econômica dentro do governo chileno. Também trouxe os perfis, baseando-se em três variáveis (formação escolar, herança política e participação em partido político), dos economistas dirigentespolíticos do período de 1973 a 1994.

Este estudo apontou que a construção do economista enquanto dirigente-político se iniciou a partir de 1958, como a literatura já apontava. Essa ascensão se deu tanto em número de bacharéis em ciência econômica como em tempo de mandato desses bacharéis. Desde 1958, o tempo de mandato de economistas em cargos de decisão da política econômica do governo tem sido superior ao tempo de mandato de outros profissionais, como engenheiros, advogados, militares etc. O tempo de mandato cresceu de forma 
significativa a partir desse momento, demonstrando o fortalecimento da presença do cientista econômico.

Outro fato diz respeito à análise dos perfis dos Chicago Boys e dos monges da CIEPLAN. A formação escolar demonstrou semelhança na titulação de bacharel em economia nos dois perfis, pois a Universidade Católica do Chile teve maior peso. Já nos cursos de pós-graduação houve diferença: enquanto grande parte dos Chicago Boys estudou, obviamente, na Universidade de Chicago, os monges da CIEPLAN se distribuíram em diversos centros de pós-graduação. Isso indica que a formação da ideologia econômica desses grupos não foi resultado do curso de economia em determinada universidade chilena, uma vez que ambos tiveram forte presença na Universidade Católica do Chile, tendo a pós-graduação representado a formação ideológica dos Chicago Boys, mas não dos monges da CIEPLAN.

A herança política e a participação em partidos políticos mostram que esses dois perfis têm diferenças. Essa duas variáveis tiveram pouco impacto nos Chicago Boys, ou seja, trata-se de um grupo que não possui parentesco direto na política e é afastado da esfera da política partidária. Já no caso dos monges da CIEPLAN, esses constituem um grupo que, além de estar envolvido em questões técnicas da política econômica, mantém, em paralelo, uma vida partidária.

Este artigo pode ser usado como base para futuros trabalhos que tenham a pretensão de estudar os agentes da economia no Chile, uma vez que esse tema, além de ter pouca literatura, possui pouquíssimos dados empíricos. Além disso, deixa em aberto algumas questões sobre como se deu a formação dos monges da CIEPLAN e qual é a influência dos partidos políticos para os economistas dirigentes-políticos no Chile.

\section{REFERÊNCIAS BIBLIOGRÁFICAS}

Diccionario biográfico de Chile: 1984-1986. Santiago: Empresa Periodística Chile.

DELAÑO, M., TRASLAVIÑA, H. 1989. La herencia de los Chicago Boys. Santiago: Ediciones del Ornitorrinco.

FONTAINE, A. 1988. Los Economistas y el Presidente Pinochet. Santiago: Zig Zag.

GOUVÊA, G. 1994. Burocracia e Elites Burocráticas no Brasil, São Paulo: Editora Paulicéia. 
GÓNGORA, M. 1981. Ensayo histórico sobre la noción de Estado en Chile en los siglos XIX y XX. Santiago: Ediciones la ciudad.

HUNEEUS, C. "El Ejército y la Política en el Chile de Pinochet, su Magnitud y Alcances". IN: Opciones, nº 14, 1988, pp. 89-136.

HUNEEUS, C. Tecnócratas y políticos en un régimen autoritario. Los "ODEPLAN Boys" y los "Gremialistas" en el Chile de Pinochet. IN: Revista de Ciência Política Vol.19 - No2, 1998, pp.125-158.

LOUREIRO, M. 1997. Os Economistas no Governo. Rio de Janeiro: Editora Fundação Getúlio Vargas.

MARKOFF, J., MONTECINOS, V. El irresistible ascenso de los economistas. IN: Desarrollo Económico, Vol. 34, No. 133 (Apr. - Jun., 1994), pp. 3-29.

MONTECINOS, V. El Valor Simbólico de los Economistas en la Democratización de la Política Chilena. IN: Revista Nueva Sociedad Número, 152, Caracas, Venezuela, Edición de Noviembre-Diciembre de 1997.

MONTECINOS, V. 1998. Economists, Politics and State: Chile 1958 - 1994. Amsterdam: CEDLA.

SILVA, P. Technocrats and politics in Chile: from the Chicago Boys to the Cieplan monks. IN: Journal of Latin American Studies, 23 (part 2), May 1991.

SILVA, P. 2006. Los tecnocratas y la politica en Chile: Pasado y Presente. IN: Revista de Ciencia Política No 02, vol. 26, Santiago de Chile.

SILVA, P. 2010. En el nombre de la razón: Tecnocratas y política en Chile, Santiago: Ediciones Universidad Diego Portales.

RAMÓN, A. 1999. Biografias de Chilenos 1976-1973: Miembros de los Poderes Ejecutivo, Legislativo y Judicial. Santiago: Ediciones Universidad Católica de Chile.

VALDÉS, J. 1989. La Escuela de Chicago: Operación Chile. Buenos Aires: Grupo Editorial Zeta S.A.

VALDÉS, J. 1995. Pinochet's Economists: The Chicago School in Chile. Cambridge: Cambridge University Press. 